\title{
MODELAGEM GEOECOLÓGICA DA SUSCETIBILIDADE AOS INCÊNDIOS NO PARQUE ESTADUAL DA LAPA GRANDE, MINAS GERAIS, BRASIL
}

SANTOS JÚNIOR, Valdevino José dos ${ }^{1}$ PRADO, Rachel Bardy ${ }^{2}$ LIMA, Evaldo de Paiva ${ }^{3}$

\begin{abstract}
Recebido em: 2020.04.02 $\quad$ Aprovado em: 2020.09.15 $\quad$ ISSUE DOI: $10.3738 / 1982.2278 .3767$
RESUMO: O presente estudo visou produzir um modelo geoecológico de suscetibilidade à ocorrência de incêndios no Parque Estadual da Lapa Grande (PELG), Minas Gerais, Brasil. Aplicando-se geotecnologias, utilizou-se o método analítico-integrativo para identificar, modelar e mapear áreas com suscetibilidade à ocorrência de incêndios florestais. Realizou-se também a validação do resultado sobrepondo ao mapa de focos de calor. O resultado apontou que, no modelo produzido, mais de 50\% da área do PELG encontra-se sob alta a extrema suscetibilidade aos incêndios. A sobreposição do mapa resultante da modelagem com o mapa de focos de calor resultou em $84 \%$ de coincidência, confirmando-se a aplicabilidade do método. Conclui-se que o modelo produzido é adequado por direcionar melhores ações para a prevenção de incêndios no PELG e na zona de amortecimento, bem como para aplicação em outras unidades de conservação no Cerrado.
\end{abstract}

Palavras-chave: Incêndio florestal; Geoprocessamento; Unidade de conservação.

\section{GEOECOLOGICAL MODELING OF WILDFIRE SUSCEPTIBILITY IN THE LAPA GRANDE STATE PARK/BRAZIL}

SDUMMARY: The present study aimed to produce a geoecological model of susceptibility to the occurrence of fires in the Lapa Grande State Park (PELG), MG, Brazil. Applying geotechnologies, the analytical-integrative method was used to identify, model and map areas with susceptibility to the occurrence of forest fires. The validation of the result was also performed by overlapping the map of heat sources. The result showed that, in the model produced, more than $50 \%$ of the PELG area is under high fire susceptibility. The overlap of the map resulting from the modeling with the map of heat sources resulted in $84 \%$ coincidence, confirming the applicability of the method. It is concluded that the model produced by directing better actions for fire prevention in the PELG and in the buffer zone, as well as for application to other conservation units in the Cerrado.

Keywords: Forest wildfire, Geoprocessing, Conservation unit.

\section{INTRODUÇÃO}

Os incêndios têm degradado diversas áreas de florestas, principalmente em Unidades de Conservação (UCs) no Cerrado brasileiro. Apesar da resiliência e da necessidade do fogo para a perpetuação de diversas espécies no Cerrado (STEVENS et al. 2016, ABREU et al. 2017), a elevada frequência de incêndios causa danos ambientais às comunidades ecológicas (WHITE; WHITE, 2016).

\footnotetext{
${ }^{1}$ ORCID ID- http://orcid.org/0000-0001-6078-5282 Engenheiro Ambiental, mestre em Engenharia de Biossistemas, doutorando em Meio Ambiente - Universidade do Estado do Rio de Janeiro (PPGMA/UERJ), Rio de Janeiro, RJ.

${ }^{2}$ ORCID ID- http://orcid.org/0000-0002-1893-4915. Bióloga, doutora em Engenharia Ambiental, pesquisadora da Embrapa Solos, Rio de Janeiro, RJ.

3 ORCID ID- http://orcid.org/0000-0003-3728-744X. Meteorologista, doutor em Meteorologia Agrícola, pesquisador da Embrapa Solos/UEP-Recife, Recife, PE.
}

Nucleus, v.17, n.2, out.2020. 
Esta degradação gera danos à manutenção e a qualidade de vida de espécimes da flora e fauna e impacta negativamente, o desenvolvimento socioeconômico e os serviços ecossistêmicos locais. Os incêndios florestais podem ocorrer em função de pressões antrópicas como: a pecuária, agricultura e reflorestamento quando mal manejados, e associados às vulnerabilidades naturais, como a incidência de raios (ABREU; SOUZA, 2016; GOBBO et al., 2016; MAGALHÃES et al., 2012; PEREIRA et al., 2016; RIBEIRO et al., 2012; WHITE;e RIBEIRO, 2011).

No Brasil foram registrados por meio do satélite de referência AQUA, 188155 focos de calor em 2016, sendo 60.556 (32\%) dos focos apenas no bioma Cerrado (INSTITUTO NACIONAL DE PESQUISAS ESPACIAIS - INPE, 2017). No ano de 2019, entre primeiro de janeiro e 11 de setembro, o Cerrado apresentou mais focos de calor que a Amazônia, foram 7304 contra 6200 (DANTAS, 2019). Houve um aumento de 67\% dos focos no Cerrado entre 2018 e agosto de 2019, totalizando no último ano o acumulado de $63698 \mathrm{~km}^{2}$ de áreas queimadas (WWF-BRASIL, 2019).

A expressão focos de calor é utilizada para interpretar o registro de calor captado na superfície do solo por sensores espaciais, tal como o sensor Advanced very high resolution radiometer (AVHRR). O sensor AVHRR capta e registra qualquer temperatura maior que $47^{\circ} \mathrm{C}$ e a interpreta como sendo um foco de calor (GIGLIO et al., 2003, BATISTA, 2004, GIGLIO et al., 2016).

A geoecologia com suporte do geoprocessamento é uma ferramenta importante no desenvolvimento de estudos, com foco no entendimento da estrutura, função e dinâmica dos elementos da paisagem, além de definir a espacialização de fenômenos, como exemplo: os incêndios florestais (FERNANDES et al., 2011).

A modelagem geoecológica configura-se como um instrumento pertinente ao entendimento da dinâmica de uma paisagem. A integração de dados utilizando geoprocessamento e análise espacial, propicia a identificação de áreas com diferentes suscetibilidades à ocorrência de incêndios florestais (SOUSA et al., 2009; SOUSA et al., 2010).

Esta técnica apresenta custo reduzido e precisão adequada ao planejamento de UC na prevenção e redução de riscos aos incêndios, complementando as metodologias convencionais de detecção visual de incêndios florestais. Entende-se suscetibilidade como o grau de probabilidade que os atributos naturais têm em condicionar, induzir ou acelerar a ocorrência de um determinado risco (SOUZA, 2005).

O mapeamento da suscetibilidade à ocorrência de incêndios é um importante instrumento de auxílio no combate ao fogo, tendo um caráter prognóstico para subsidiar o planejamento de atividades de prevenção. Estudos de modelagem da suscetibilidade aos incêndios são necessários no Brasil (FERNANDES et al., 2011; TORRES et al., 2017). 
Estudando-se a espacialização das áreas suscetíveis aos incêndios, pode indicar regiões mais sensíveis ao fenômeno, o qual pode acarretar impactos negativos sobre os serviços ecossistêmicos de uma UC, tais como: a provisão de água para abastecimento, regulação do regime de fogo, valores culturais e a formação e fertilidade de solos, entre outros (DECHOUM e ARELLANO, 2016; MADUREIRA et al., 2013).

Neste sentido, o objetivo deste trabalho foi construir um modelo para identificar e mapear as áreas com maior suscetibilidade à ocorrência de incêndios florestais no Parque Estadual da Lapa Grande e em sua zona de amortecimento, Minas Gerais, Brasil.

\section{MATERIAL E MÉTODO}

\section{Área de estudo}

O Parque Estadual da Lapa Grande (PELG) é uma Unidade de Conservação de Proteção Integral, administrado pelo Instituto Estadual de Florestas de Minas Gerais (IEF/MG) e pela Companhia de Saneamento de Minas Gerais (COPASA) (MINAS GERAIS, 2006). Localiza-se entre as coordenadas geográficas $16^{\circ} 39^{\prime} 38^{\prime \prime}$ de latitude Sul e $43^{\circ} 57^{\prime} 02^{\prime \prime}$ de longitude Oeste, no município de Montes Claros, Minas Gerais (MG), Brasil (Figura 1).

Figura 1 - Localização do Parque Estadual da Lapa Grande (PELG), MG.
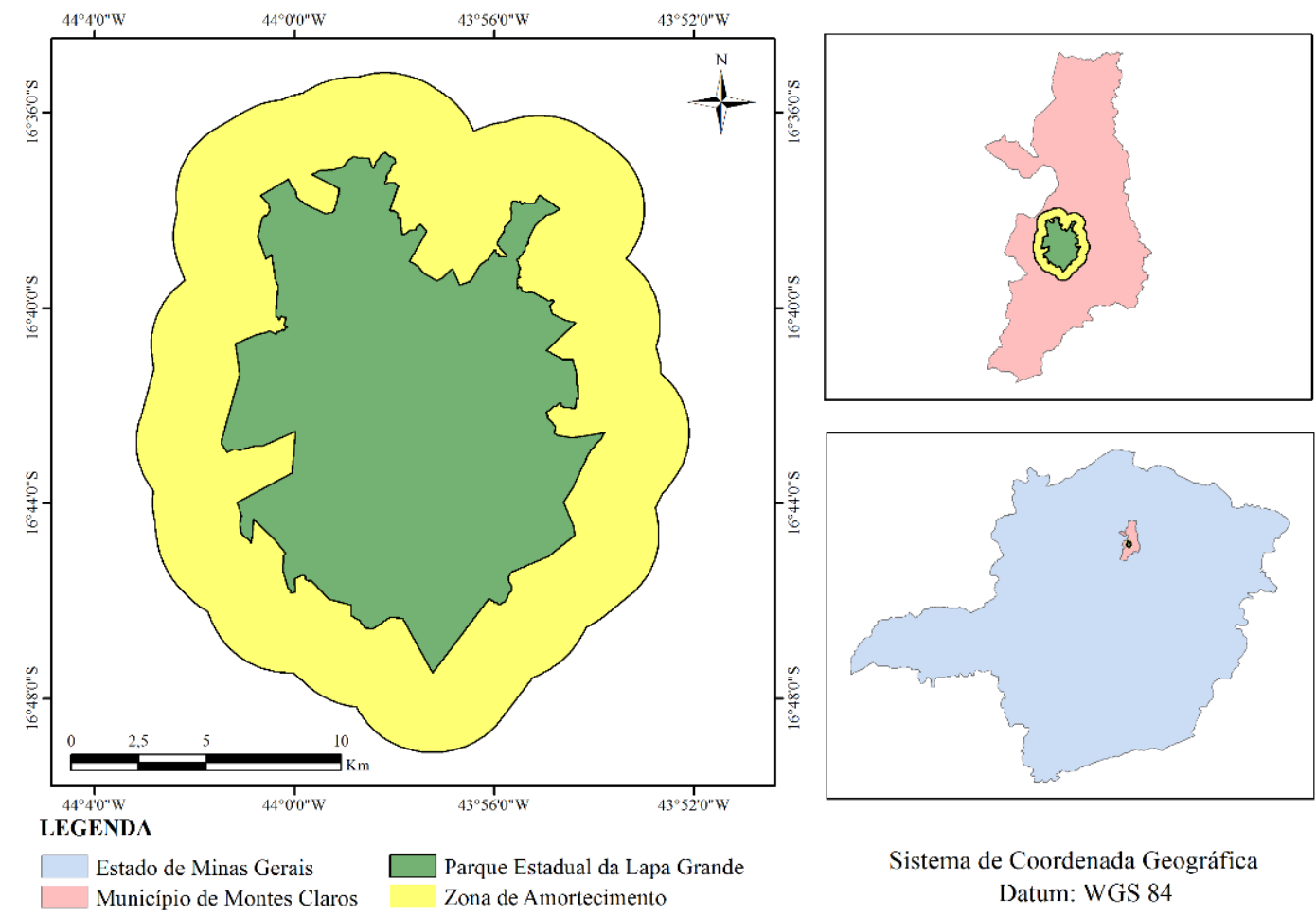

Sistema de Coordenada Geográfica Datum: WGS 84 
O Parque Estadual da Lapa Grande está inserido na região de ocorrência do bioma Cerrado, sendo este predominante em Minas Gerais (PEREIRA et al., 2016). O clima na área de estudo é o tropical semiúmido, com temperatura média anual de $24^{\circ} \mathrm{C}$. O período chuvoso concentra-se entre os meses de novembro e março, e o período seco entre os meses de abril e setembro (MOREIRA et al., 2013).

O Parque Estadual da Lapa Grande, criado pelo Decreto Estadual n 44.204/2006, tem como objetivo a proteção e conservação do complexo de grutas e abrigos da Lapa Grande. O parque apresenta fragmentos de Floresta Estacional Decidual (Mata Seca), onde situam os principais rios que abastecem Montes Claros e municípios vizinhos (IEF, 2014a; MOREIRA et al., 2013; OLIVEIRA et al., 2015; PEREIRA et al. 2016).

O Parque representa uma área estratégica para a conservação dos recursos naturais e dos aspectos históricos e socioculturais da região, dada pela presença de sítios espeleológicos e arqueológicos, bem como pelas comunidades rurais por ele englobadas (INSTITUTO ESTADUAL DE FLORESTAS - IEF, 2015). A sociedade beneficia-se direta e indiretamente do PELG, por ele gerar empregos diretos, receber visitação pública, pesquisas científicas e por conter importantes nascentes de rios, responsáveis pelo abastecimento de água de cerca de $40 \%$ do município de Montes Claros e adjacências (IEF, 2009; IEF, 2014b).

Os incêndios são recorrentes no PELG, os últimos ocorreram em 2015 e 2017 - a maior queimada consumiu 15 mil hectares do parque (FREITAS, 2019; ODA, 2015a; ODA, 2015b; PEIXOTO, 2017).

Segundo o WWF-Brasil (2016) o PELG tem 100\% de importância biológica e 74\% de importância socioeconômica; demonstrando-se o alto grau de proteção do parque para as espécies ameaçadas, os níveis elevados de diversidade biológica, a função crítica na paisagem por possuírem áreas importantes para a alimentação, reprodução, migração e dispersão de espécies. Tudo isso pode ser colocado em risco no caso de incêndios florestais na área.

\section{Modelagem geoecológica de suscetibilidade à ocorrência de incêndios}

A sequência metodológica utilizada neste estudo está apresentada na Figura 2 e foi baseada nos trabalhos de Coelho Netto et al. (2007), Coura et al. (2009), Coura et al. (2010), Fernandes et al. (2011) e Sousa et al. (2010). O levantamento bibliográfico, de material cartográfico e informações ambientais constituiu na primeira etapa da pesquisa, em que foram levantados os elementos básicos para a modelagem geoecológica. O método analítico-integrativo foi utilizado neste estudo e com ele é possível identificar, mapear e modelar com base geoecológica, áreas com suscetibilidade à ocorrência de incêndios florestais. 
Figura 2 - Etapas da modelagem geoecológica de suscetibilidade à ocorrência de incêndios.

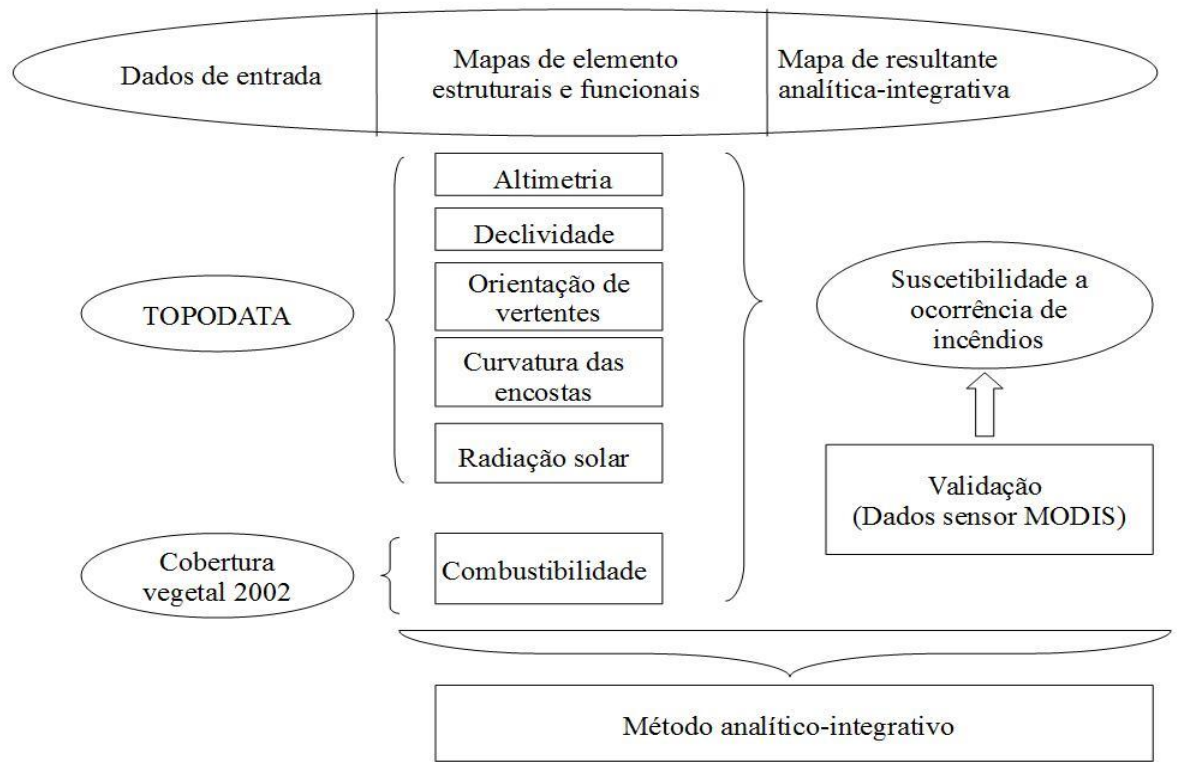

A modelagem foi iniciada a partir do modelo digital de elevação, o TOPODATA, derivado de dados do SRTM (Shuttle Radar Topographic Mission), com tamanho de pixel de 30 m, disponibilizados pelo Instituto Brasileiro de Pesquisas Espaciais (INPE). O modelo TOPODATA torna acessível um conjunto de dados para análise geomorfométrica, apresentando diversas variáveis a partir da altimetria (VALERIANO, 2008). Foi utilizada a quadrícula 16s45, correspondente ao PELG, com escala 1:250.000, em formato GeoTiff.

Desta forma, as variáveis altitude, declividade, orientação de vertentes e curvatura horizontal foram utilizadas e serviram como dados de entrada no software ArcGIS $10.1^{\circledR}$, como também utilizado por Gomes et al. (2019). Além delas, utilizou-se a radiação solar, a cobertura vegetal e o perímetro do PELG. As respectivas variáveis foram selecionadas em função de estudos prévios, tais como: Coura et al. (2009), Fernandes et al. (2011) e Sousa et al. (2010) em que estas variáveis influenciam a suscetibilidade à ocorrência de incêndios florestais.

Por meio do modelo digital de elevação, o TOPODATA (SRTM), que é disponibilizado gratuitamente e utilizado amplamente em estudos de modelagem geoecológica, tem-se a altimetria, e partir dela foi obtida a radiação solar, utilizando-se a ferramenta Solar radiation do ArcGIS ${ }^{\circledR}$. A radiação solar é dada em $\mathrm{Wh} / \mathrm{m}^{2}$ e foi dividida em três classes, de A a C.

Para a variável cobertura vegetal, utilizou-se dados do PROBIO, na escala 1:250.000 disponibilizado pelo Ministério do Meio Ambiente (MMA, 2002). A cobertura vegetal, conforme explicita Fernandes et al. (2011), representa a combustibilidade da própria vegetação. 
O perímetro do PELG foi obtido por meio da administração do parque e equivale a $3 \mathrm{~km}$, visto que este parque não possui ainda um Plano de Manejo, sendo esta faixa estabelecida pelo Conselho Nacional de Meio Ambiente (Conama). Sendo assim, foi aplicado um buffer de $3 \mathrm{~km}$ sobre a área do PELG, visando obter a perímetro da zona de amortecimento (ZA). Posteriormente, foram realizados recortes dos rasters dos mapas temáticos usados no estudo, utilizando-se este buffer. Esse procedimento também foi realizado por Gobbo et al. (2016) e Pereira et al. (2012).

Os mapas temáticos de altimetria, declividade, orientação e curvatura das encostas, radiação solar e de cobertura vegetal, foram gerados no ArcGIS 10.1. Os mapas uma vez obtidos foram classificados quanto a suscetibilidade e as classes receberam distintos valores, conforme os estudos de Assis et al. (2014), Koproski et al. (2011) e Ribeiro et al. (2012) (Tabela 1).

Tabela 1 - Classificação temática da suscetibilidade à ocorrência de incêndios.

(Continua)

\begin{tabular}{|c|c|c|}
\hline Altimetria (m) & Risco & Valores \\
\hline Até 600 & Extremo & 5 \\
\hline $600-900$ & Muito alto & 4 \\
\hline $900-1200$ & Alto & 3 \\
\hline $1200-1500$ & Moderado & 2 \\
\hline Acima de 1500 & Baixo & 1 \\
\hline \multicolumn{3}{|l|}{ Declividade (\%) } \\
\hline Até 15 & Baixo & 1 \\
\hline $16-25$ & Moderado & 2 \\
\hline $26-35$ & Alto & 3 \\
\hline $35-45$ & Muito alto & 4 \\
\hline Acima de 45 & Extremo & 5 \\
\hline \multicolumn{3}{|c|}{ Orientação de encostas } \\
\hline $\mathrm{SE} / \mathrm{S} / \mathrm{SW}$ & Baixo & 1 \\
\hline $\mathrm{E}$ & Moderado & 2 \\
\hline $\mathrm{NE}$ & Alto & 3 \\
\hline NW/W & Muito alto & 4 \\
\hline $\mathrm{N}$ & Extremo & 5 \\
\hline \multicolumn{3}{|c|}{ Curvatura de encostas } \\
\hline Convergente & Baixo & 1 \\
\hline Plana & Moderado & 3 \\
\hline
\end{tabular}


Tabela 1 - Classificação temática da suscetibilidade à ocorrência de incêndios.

(Conclusão)

\section{Radiação solar $\left(\mathrm{Wh} / \mathbf{m}^{2}\right)$}

\begin{tabular}{lll}
\hline A $(718088,43-775720,38)$ & Baixo & 1 \\
\hline B $(775720,39-787853,42)$ & Alto & 3 \\
\hline C $(787853,42-804030,81)$ & Extremo & 5
\end{tabular}

\section{Cobertura do solo}

Floresta Estacional Decidual Baixo 1

de Montana

Pastagem cultivada Extremo 5

Fonte: Adaptado de Assis et al. (2014), Koproski et al. (2011), Ribeiro et al. (2012).

A Tabela 2 apresenta as variáveis estudadas e os respectivos pesos. Esses foram extraídos, após um levantamento bibliográfico dos estudos de Assis et al. (2014), Koproski et al. (2011), Ribeiro et al. (2012), Santos et al. (2010) e Torres et al. (2017). Os pesos podem ser entendidos como graus de influência de cada variável na paisagem, sendo possível criar modelos para determinar áreas mais suscetíveis aos incêndios.

Tabela 2 - Variáveis utilizadas na modelagem e respectivos pesos.

\begin{tabular}{ll}
\hline Variáveis & Pesos \\
\hline Altitude & 0,25 \\
\hline Declividade & 0,75 \\
\hline Orientação & 0,75 \\
\hline Curvatura & 0,50 \\
\hline Radiação solar & 0,75 \\
\hline Cobertura vegetal & 2,00
\end{tabular}

Fonte: Assis et al. (2014), Koproski et al. (2011), Ribeiro et al. (2012), Santos et al. (2010) e Torres et al. (2017).

Foi realizada a operação de matrizes com as seis variáveis aplicando a Equação 1 e considerando-se os graus de influência da Tabela 2 sob cada variável, como realizado por Assis et al. (2014) e Koproski et al. (2011). 
Suscetibilidade $=\left(0,25^{*}\right.$ Altitude $+0,75^{*}$ Declividade $+0,75^{*}$ Orientação $+0,5 *$ Curvatura + $0,75 *$ Radiação Solar $+2 *$ Cobertura vegetal $/ 5$ )

A análise espacial foi realizada utilizando-se a ferramenta raster calculator do software ArcGis $10.1^{\circledR}$ com base nas informações das Tabelas 1 e 2, e aplicando-se a Equação 1. Desta forma, o mapa de modelagem da suscetibilidade geoecológica à ocorrência de incêndios para o PELG, foi separado em cinco classes de suscetibilidade: baixa, moderada, alta, muito alta e extrema.

Para a validação do modelo de suscetibilidade, foram utilizados dados do sensor Moderate Resolution Imaging Spectroradiometer (MODIS), acoplado no satélite-referência AQUA. Esse satélite é muito utilizado na detecção de focos de calor (FERNANDES et al., 2011; PEREIRA et al., 2012; SANTOS et al., 2018).

Os focos de calor foram obtidos gratuitamente do banco de dados de queimadas do Instituto Nacional de Pesquisas Espaciais (INPE), entre o período de 01/01/2015 a 31/12/2015, (ano que houveram grandes incêndios no PELG). Foi aplicado sobre cada um dos pontos de focos de calor um buffer de $500 \mathrm{~m}$, formando, portanto, uma área circular de $1 \mathrm{~km}$ de diâmetro, visando a validação da suscetibilidade a incêndios no PELG. Tal procedimento também foi realizado por Fernandes et al. (2011). Posteriormente, os buffers foram sobrepostos ao mapa de suscetibilidade, com intuito de averiguar a validade do modelo criado.

\section{RESULTADO E DISCUSSÃO}

Os mapas temáticos produzidos para a geração do mapa final estão apresentados na Figura 3. As seis classes temáticas altimetria, declividade, orientação das encostas, curvatura das encostas, radiação solar e cobertura vegetal, variaram de baixa a extrema suscetibilidade à ocorrência de incêndios.

A altimetria no Parque Estadual da Lapa Grande e ZA variou entre 625 a 1037 m, com altimetria média de $843,3 \mathrm{~m}$, isto é, apresentou um Alto risco à suscetibilidade aos incêndios. Diferentemente, a declividade alternou entre 0,25 e $84,17 \%$ (média de 14,6\%), predominando o risco Baixo de suscetibilidade à ocorrência de incêndios. A orientação de encostas indicou que $31,92 \%$ das faces estão voltadas para o Norte, $16,11 \%$ para o Noroeste e Oeste, $11,83 \%$ para o Nordeste, apontando que, 59,86\% da área do PELG tem de Alto a Extremo risco à ocorrência de incêndios.

A curvatura divergente das encostas mostrou-se predominante na área pesquisada, apresentando 43,65\%, ou seja, Alto risco de suscetibilidade à ocorrência de incêndios, contra 
$36,70 \%$ de áreas convergentes e 19,67\% de áreas planas. A radiação solar apresentou 75,87\% de risco de Moderada a Alta suscetibilidade à ocorrência de incêndios. A cobertura do solo predominante é a pastagem, representando 58,69\% da área do PELG e ZA. 
Figura 3 - Mapas temáticos utilizados na modelagem de suscetibilidade aos incêndios.

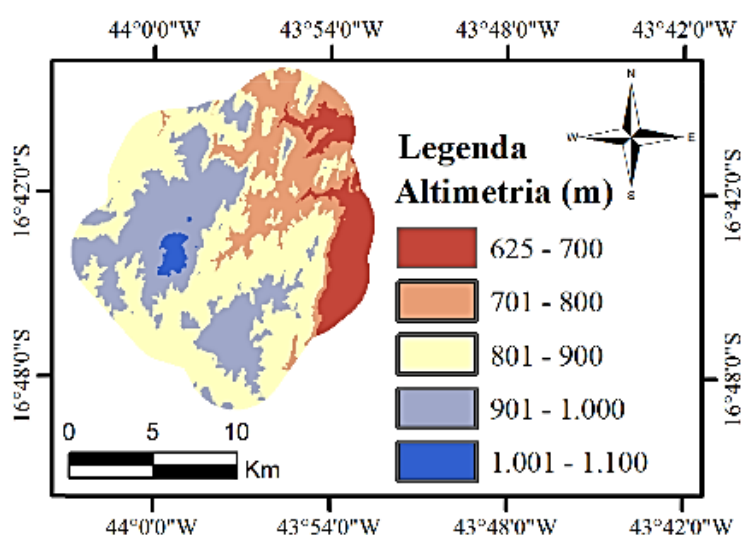

3A. Mapa de altimetria

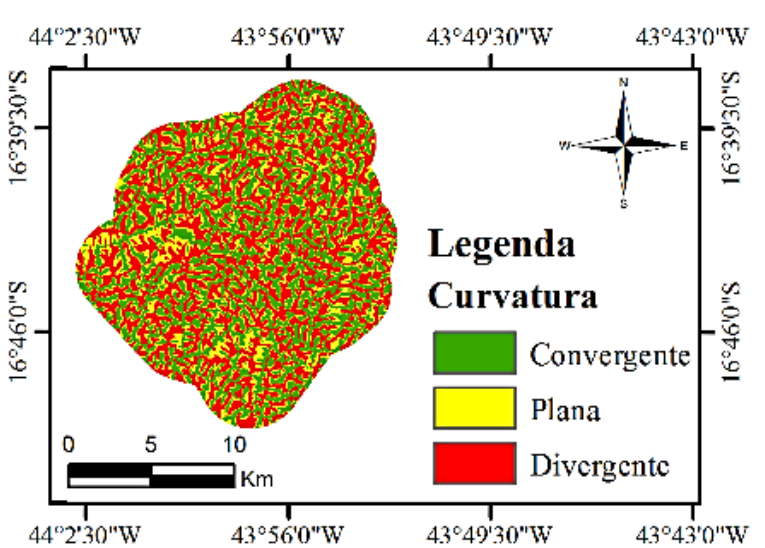

3D. Mapa de curvatura de encostas

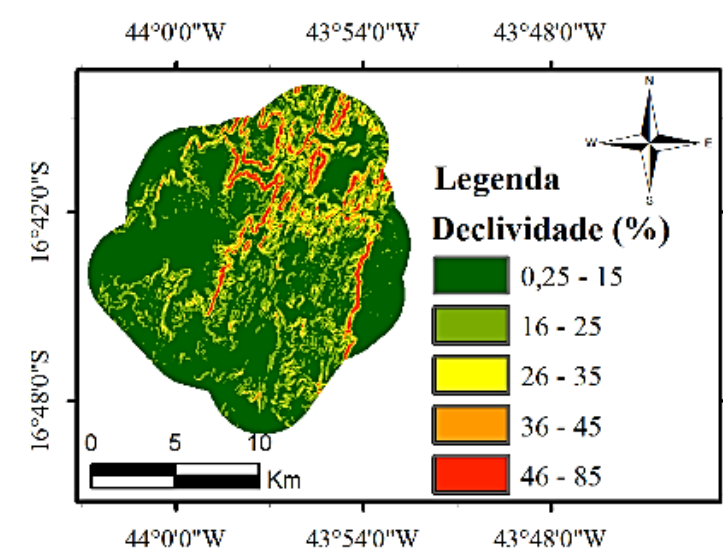

3B. Mapa de declividade

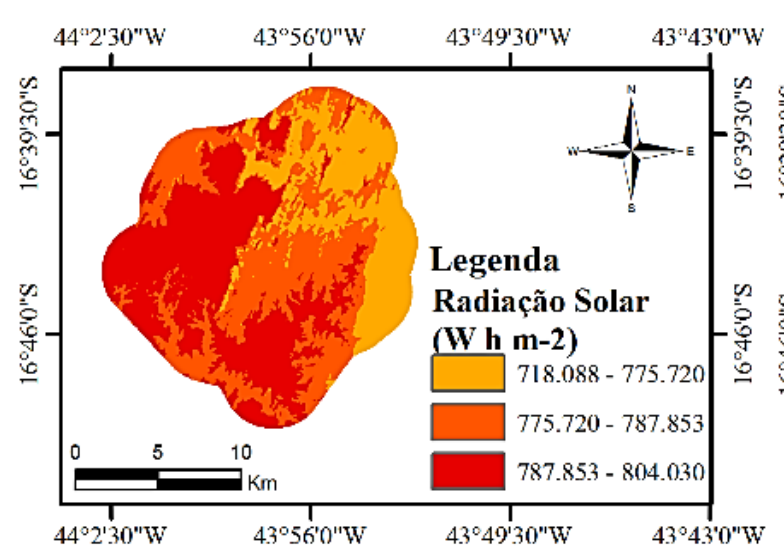

3E. Mapa de radiação solar

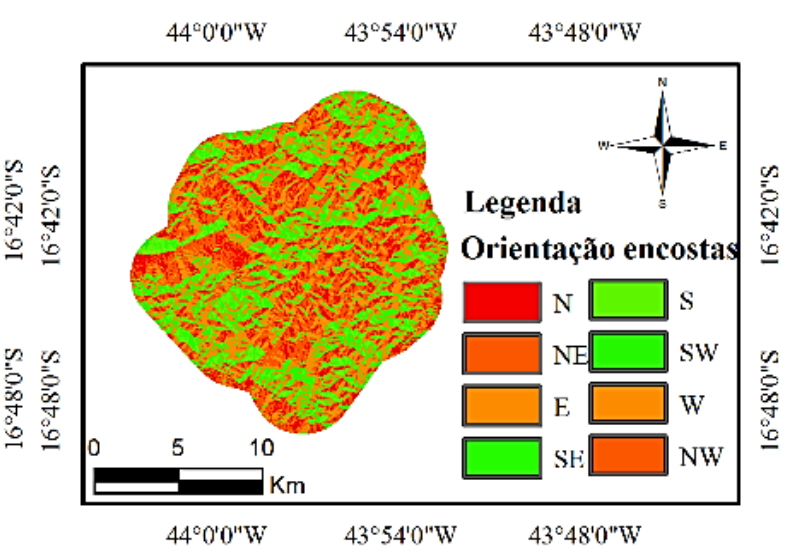

3C. Mapa de orientação de encostas

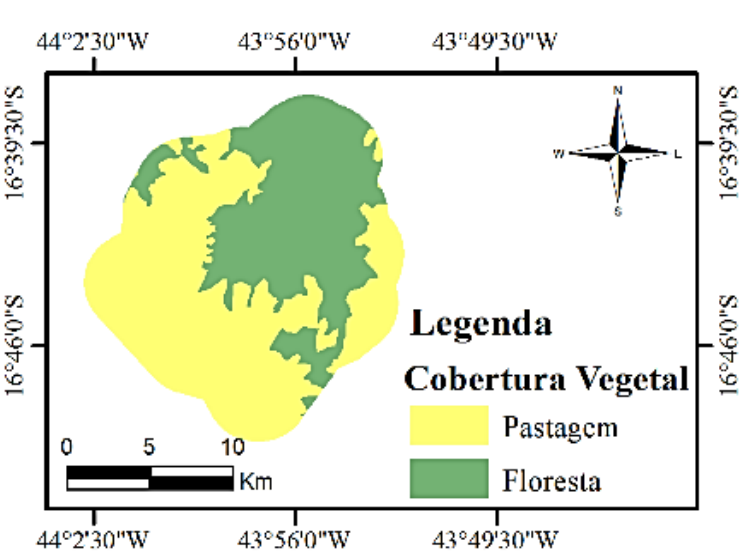

3F. Mapa de cobertura vegetal

\section{Projeção UTM}

Datum SAD 69 - Fuso 23S 
O mapa de modelagem da suscetibilidade geoecológica à ocorrência de incêndios para o PELG e ZA está apresentado na Figura 4. A distribuição espacial da suscetibilidade na área pesquisada resultou em cinco classes: Baixa $(3,75-6,72)$, Moderada $(6,72-8,23)$, Alta $(8,23-9,48)$, Muito alta $(9,48-10,73)$ e Extrema $(10,73-14,75)$.

Figura 4 - Mapa de suscetibilidade à ocorrência de incêndios no PELG.

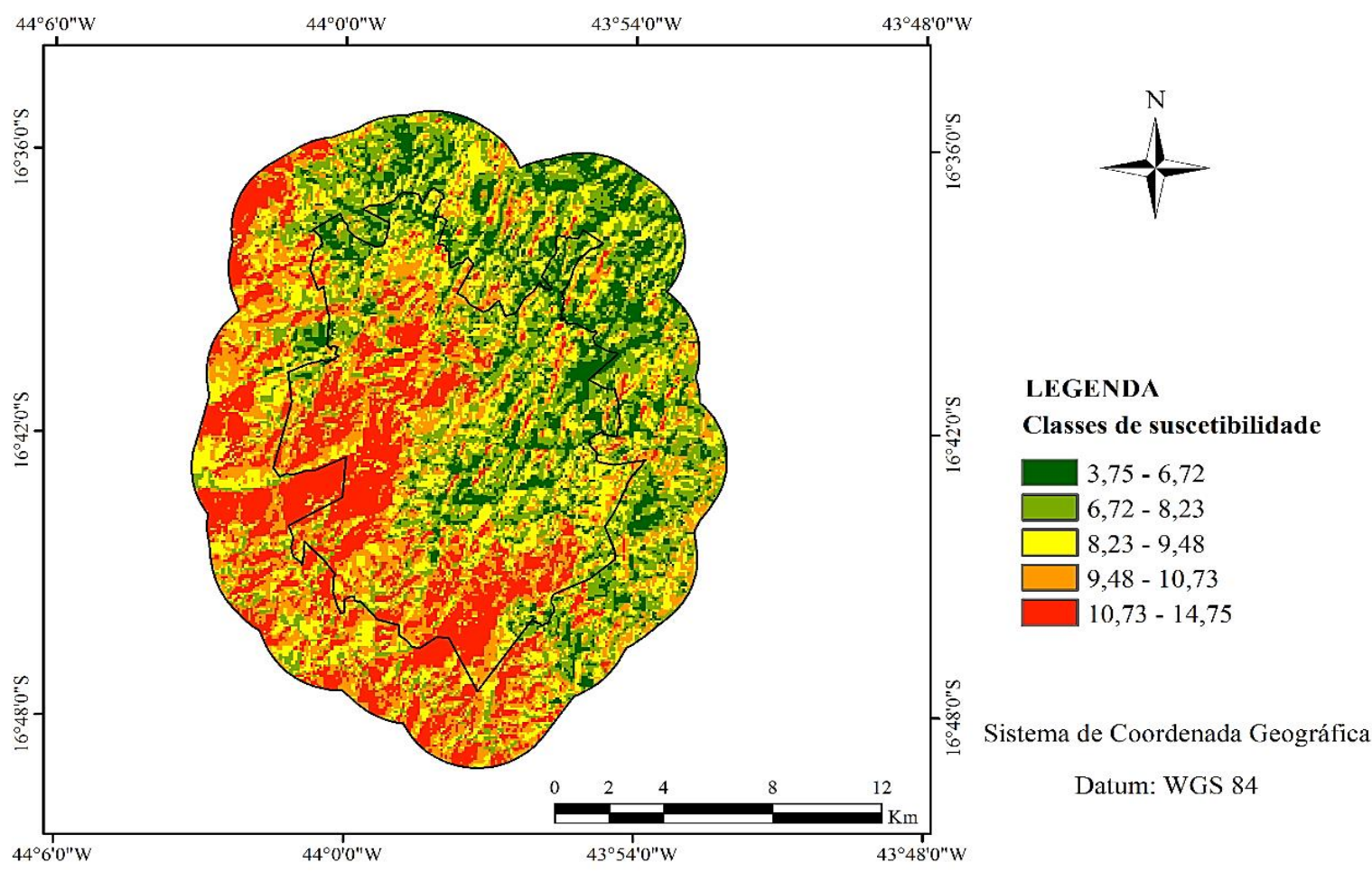

De maneira geral, observa-se que as regiões Oeste e Sul, principalmente na ZA do PELG, apresentaram elevada suscetibilidade à ocorrência de incêndios. As seis variáveis (altitude, declividade, orientação, curvatura, radiação solar e cobertura vegetal), utilizadas na composição do mapa, podem indicar o acesso, propagação e extensão do fogo para a ocorrência de incêndios. Isto também foi destacado por Torres et al. (2014).

As variáveis que mais propiciaram para os resultados de maior risco de suscetibilidade nas regiões Oeste e Sul do PELG foram, em ordem decrescente: cobertura vegetal, radiação solar, orientação, declividade, curvatura e por fim, altitude, em função dos pesos recebidos e da manifestação dos valores de risco mais elevados. A associação de pastagem, radiação solar extrema e curvatura divergente foram decisivos para os resultados. Segundo Santos Júnior, Lima e Prado (2016) as variáveis se inter-relacionam influenciando no comportamento uma das outras.

A altitude afeta as condições climáticas locais e por consequência, atua nas características de umidade do material combustível. Quanto maior a altitude, maior a umidade e, por 
conseguinte, menor a suscetibilidade à ocorrência de incêndios. Geralmente, baixas elevações tendem a apresentar maior risco de incêndios devido à menor umidade. Os fundos de vale e topos de montanha possuem diferentes condições de queima no período diurno devido às diferenças na radiação solar (RIBEIRO et al., 2008).

Para Batista (2000) a topografia altera as condições climáticas e influencia no tipo de combustível de uma região, influenciando também no comportamento do fogo. Desta forma, pode-se dizer que a topografia influi decisivamente no comportamento do fogo, pela influência física sobre a inclinação das chamas, elevando consideravelmente a fase de pré-aquecimento da reação da combustão, proporcionando uma maior suscetibilidade à ocorrência de incêndios.

Isto também é apontado por Ribeiro et al. (2008) que, em áreas de aclive acentuado a tendência do fogo é de se propagar com maior intensidade, e em declives isso ocorre mais lentamente. Um incêndio florestal se propagando em um aclive acentuado, assemelha-se a um incêndio propagando-se numa área plana, sob efeito de fortes ventos.

Sobre a curvatura das encostas, as áreas convergentes possuem maior umidade por serem regiões côncavas. As divergentes são áreas convexas, tendendo a serem mais secas e, por ficarem mais expostas à radiação solar, são mais suscetíveis à ocorrência de incêndios. Enquanto que as áreas planas dependem da declividade do local (NUNES et al., 2015).

Encostas com diferentes orientações, curvaturas e inclinações recebem quantidades diferentes de radiação solar global, se comparadas às superfícies horizontais em uma mesma época do ano, numa mesma localidade. As orientações voltadas para entre o Norte e Oeste, as curvaturas divergentes e encostas com maiores inclinações (maior declividade) tendem a receber maior quantidade de radiação solar. Isto influencia na secagem de diferentes tipos de materiais combustíveis, em cada encosta e/ou inclinação (SOARES NETO et al., 2016, TORRES et al. 2014; TORRES et al. 2017).

Além desses elementos, adiciona-se a propagação do fogo, a qual em locais com alguma declividade, tem um comportamento diferente se comparado àquele que ocorre em áreas sem declividade devido ao efeito de fatores adicionais, como a convecção e a radiação solar, as quais, mesmo atuando em áreas planas; mas em áreas inclinadas condicionam a aceleração do fogo, alastrando-o (VIEGAS, 2004).

Torres (2006) dissertou que as encostas contêm peculiaridades, sendo elas: no seu terço inferior as temperaturas são mais altas havendo, necessariamente, mais vegetação; no terço médio durante o período noturno, são formadas colunas térmicas (ar mais quente na porção intermediária da encosta); no terço superior ocorrem variações bruscas de ventos, contendo menos vegetação. Essas diferenciações ocorrem devido ás ondas que são irradiadas a partir do 
solo elevando a temperatura do ar no sentido ascendente, portanto a temperatura vai diminuindo das porções inferiores para as superiores.

As características do material combustível influenciam diretamente na propagação do fogo (SOARES NETO et al., 2016). O tipo e disposição do material combustível pode facilitar a ignição do fogo, por exemplo: um material fino exige menor temperatura de ignição e perde umidade com mais facilidade, ou seja, facilita o início e a acelera a propagação do incêndio. Em áreas onde a distribuição do combustível é uniforme e com maior proximidade de partículas do material combustível, propicia a propagação do fogo. Este caso é facilmente visualizado em áreas de pastagem ou lotes vagos, geralmente forrados por gramíneas (TORRES et al., 2014). A cobertura vegetal com maior presença de pastagem contribui, portanto, para a maior suscetibilidade à ocorrência de incêndios.

A Tabela 3 apresenta as áreas de distribuição espacial das classes de suscetibilidade à ocorrência de incêndios, dada $\mathrm{em}^{\mathrm{km}}{ }^{2}$ e em porcentagem.

Tabela 3 - Valores de áreas obtidos em cada classe de suscetibilidade, em $\mathrm{km}^{2}$ e porcentagem.

\begin{tabular}{lll}
\hline Classes de suscetibilidade & Suscetibilidade $\mathbf{( \mathbf { k m } ^ { \mathbf { 2 } } )}$ & Suscetibilidade $(\boldsymbol{\%})$ \\
\hline Baixa & 47,04 & 12,50 \\
\hline Moderada & 84,40 & 22,43 \\
\hline Alta & 87,86 & 23,35 \\
\hline Muito alta & 77,51 & 20,60 \\
\hline Extrema & 79,47 & 21,12 \\
\hline TOTAL & $\mathbf{3 7 6 , 2 8}$ & $\mathbf{1 0 0 , 0 0}$ \\
\hline
\end{tabular}

No modelo de suscetibilidade resultou que 65,07\% (244,84 $\left.\mathrm{km}^{2}\right)$ da área do PELG e ZA está entre alta e extrema suscetibilidade à ocorrência de incêndios. O restante (34,93\%, 131,44 $\mathrm{km}^{2}$ ) equivale às áreas menos suscetíveis ao fenômeno, correspondendo às classes de suscetibilidade baixa e moderada.

Brito e Ferreira (2015) utilizaram o estimador de densidade Kernel na quantificação da suscetibilidade à ocorrência de incêndios florestais para o Estado de Goiás. Eles identificaram que o Estado encontra-se sob um baixo risco de incêndios (67,35\%). Verificou-se também que nas porções Norte e Leste goiano demonstraram ter maior suscetibilidade à ocorrência de incêndios. Isso pode estar relacionado à disponibilidade de material combustível do Cerrado ainda bem conservada no Norte e, as grandes áreas com atividades agrícolas no Leste goiano.

No mesmo sentido, Miranda et al. (2004) afirmam que as áreas de Cerrado apresentam grande concentração de material combustível em condições favoráveis para ocorrência e 
propagação do fogo, conforme a estação do ano. Esses achados confirmam com os resultados do presente estudo, ao confirmar que a variável cobertura vegetal, é um fator que influenciou fortemente na modelagem da suscetibilidade aos incêndios.

A cobertura vegetal, ou seja, o material combustível para Torres et al. (2014), é determinante na ocorrência de fogo. O tipo de material combustível e a sua disposição facilitam a ignição e propagação do fogo. O material fino, por exigir menor temperatura de ignição e por perder rapidamente umidade, facilita o início do incêndio e acelera sua propagação. Essa situação é maximizada quando há distribuição uniforme e maior proximidade entre partículas do material combustível, acarretando a propagação do fogo em áreas de pastagens e de lotes vagos, comumente forrados por gramíneas.

Apesar de algumas espécies do bioma Cerrado serem adaptadas ao fogo, estudos sugerem que a recorrência de queimadas podem mudar a fisionomia do Cerrado para campos abertos, tornando as gramíneas o principal componente herbáceo. Isso resultaria em um maior acúmulo de biomassa, acarretando na maior frequência de incêndios com altas temperaturas, podendo prejudicar a fauna e a flora, além de expor o solo aos processos erosivos e de lixiviação (MIRANDA et al., 2002; SANTOS et al., 2018).

Armenteras-Pascual et al. (2011), na Colômbia, comparou o tamanho de áreas queimadas de acordo com o tipo de vegetação. Eles mostraram que a vegetação campestre foi o tipo mais queimado, seguido por capoeiras, florestas e áreas agrícolas. O padrão para o número de ocorrências na validação dos dados foi bastante diferente. Entretanto, a vegetação campestre mostrou o valor mais alto de ocorrências, seguida de perto por zonas agrícolas, florestas e capoeiras.

De acordo com Ribeiro et al. (2012) as atividades produtivas no entorno de florestas, influenciam diretamente na suscetibilidade à ocorrência de incêndios, ocasionando alteração no ambiente e nas características físico-químicas da vegetação. $\mathrm{O}$ fogo acomete as zonas de savana, floresta ombrófila aberta e de transição e principalmente, as áreas de pastagem no entorno do Parque Estadual do Cristalino I e II. Os autores identificaram que 58,7\% da área no município de Novo Mundo, MS, têm risco de incêndio florestal entre muito alto e extremo, resultado semelhante ao encontrado no PELG e ZA.

Torres et al. (2014) destacou que a principal causa de incêndios florestais no Brasil, é decorrente de atividades humanas no meio rural, dadas por diversas práticas, que podem ser desde um simples descuido até o uso doloso do fogo.

As maiores pressões antrópicas sofridas por Unidades de Conservação são provenientes das zonas de amortecimento, em função do avanço dos usos inadequados do solo e dos recursos naturais. A extração de componentes da flora e fauna e avanço das zonas urbana e agropecuária, 
até a ocorrência de incêndios criminosos e acidentais são comuns nas bordas das UCs (BEIROZ, 2015).

Essas questões se relacionam à ZA do PELG, tendo a pastagem como a principal atividade antrópica da região (OLIVEIRA et al., 2015). Também é importante mencionar que a população tem fácil acesso a estas áreas, havendo processos de urbanização, presença de uma indústria, além de rodovias que cruzam a área.

Abreu e Souza (2016) e White et al. (2016) apontam que quanto maior a densidade demográfica e a presença de sistema viário em uma região, maior é a suscetibilidade à ocorrência de incêndio florestal. Desta forma, é necessário criar ações de prevenção aos incêndios na ZA e no interior do PELG, levando-se em conta a densidade populacional da ZA e a presença da malha viária, além das variáveis consideradas na presente modelagem.

Quanto aos focos de calor oriundos do sensor MODIS, pode-se verificar, para o ano de 2015, que 52 pontos de focos de calor foram detectados no interior e na ZA do PELG. Destaca-se que os focos de calor ocorreram principalmente no início de novembro, sendo que nesse mês houve um grande incêndio no PELG.

A Figura 5 apresenta a distribuição espacial da sobreposição das áreas de focos de calor com o resultado encontrado na presente modelagem. Com isto, verificou-se que $84 \%$ da área do PELG se encontra sob alta a extrema suscetibilidade à ocorrência de incêndios.

Figura 5 - Sobreposição da distribuição espacial das áreas de focos de calor com as áreas resultantes da modelagem.

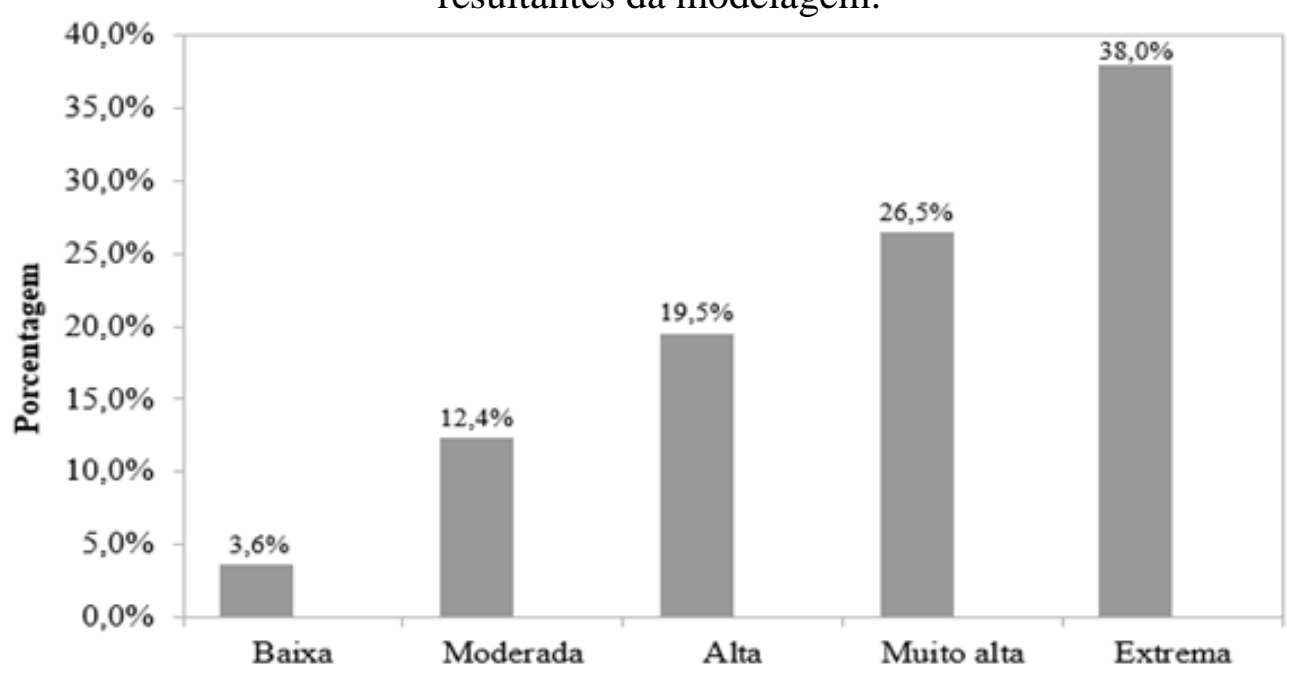

- Suscetibilidade

Um modelo de suscetibilidade para ser validado, necessita de um percentual de acerto igual ou maior a 60\% (WHITE et al., 2016). Desse modo, o mapa de suscetibilidade e a sobreposição foi de $84 \%$ (soma das porcentagens de alta a extrema suscetibilidades). Por tanto, o modelo foi validado. 
O modelo de suscetibilidade produzido pode fornecer subsídios para o planejamento e a tomada de decisões relacionadas aos incêndios florestais, uma vez que identificou a distribuição espacial das classes de suscetibilidade à ocorrência de incêndios. Indo ao encontro do relatado por Silva et al. (2008), que o mapa de suscetibilidade pode auxiliar ações de prevenção, combate e controle de incêndios por parte da sociedade civil organizada e do poder público.

\section{CONCLUSÃO}

A modelagem geoecológica mostrou-se uma importante ferramenta para auxiliar no combate aos incêndios em unidades de conservação no Brasil, com destaque ao caso do Parque Estadual de Lapa Grande.

O modelo produzido para o PELG apontou que mais de 50\% das áreas do parque e sua zona de amortecimento estão sob alta a extrema suscetibilidade à ocorrência de incêndios, devido principalmente às variáveis cobertura vegetal (pastagem), radiação solar e orientação de encostas, pois receberam maiores pesos e apresentaram as categorias com alto risco de suscetibilidade à ocorrência de incêndios.

A validação é uma etapa importante da modelagem, e no presente estudo obteve-se que os focos de calor oriundos de imagens de satélite coincidem com as áreas de alta a extrema suscetibilidade à ocorrência de incêndios no PELG e ZA, confirmando, assim, a aplicabilidade do modelo. Contudo, recomenda-se para outros estudos que a validação possa ser feita com uma série temporal de imagens mais longa e também com informações sobre focos de incêndios obtidas por observação em campo.

Apesar do modelo ter incorporado apenas fatores naturais, os fatores antrópicos não devem ser ignorados, uma vez que são também os responsáveis pelo desencadeamento de incêndios florestais.

O modelo de suscetibilidade produzido pode ser adotado na alocação de recursos para auxiliar na prevenção e combate aos incêndios no PELG e entorno, podendo ser adaptado e aplicado em outras unidades de conservação com a mesma problemática.

\section{REFERÊNCIAS}

ABREU, F. A. et al. The biodiversity cost sequestration in tropical savanna. Science Advances, [s.l.], v. 3, 2017.

ABREU, F. A.; SOUZA, J. S. A. Dinâmica espaço-temporal de focos de calor em duas terras indígenas do Estado de Mato Grosso: uma abordagem geoespacial sobre a dinâmica do uso do fogo por Xavantes e Baroros. Floresta e Ambiente, Seropédica, v. 23, n. 1, 2016. DOI: https://doi.org/10.1590/2179-8087.041813. 
ARMENTERAS-PASCUAL, D. et al. Characterising fire spatial pattern interactions with climate and vegetation in Colombia. Agricultural and Forest Meteorology, [s.1.], v. 151, 2011. DOI: doi:10.1016/j.agrformet.2010.11.002

ASSIS, R. V. et al. Uso de geotecnologias na locação espacial de torres para detecção de incêndios florestais no semiárido nordestino. Floresta, Curitiba, v. 44, n. 1, 2014. DOI: http://dx.doi.org/10.5380/rf.v44i1.32618.

BATISTA, A. C. Detecção de incêndios florestais por satélite. Floresta, Curitiba, v. 34, n. 2, 2004. DOI: http://dx.doi.org/10.5380/rf.v34i2.2402.

BATISTA, A. C. Mapas de risco: uma alternativa para o planejamento de controle de incêndios florestais. Floresta, Curitiba, v. 30, n. 1, 2000. DOI: http://dx.doi.org/10.5380/rf.v30i12.2328.

BEIROZ, H. Zonas de amortecimento de Unidades de Conservação em ambientes urbanos sob a ótica territorial: reflexões, demandas e desafios. Desenvolvimento e Meio Ambiente, Curitiba, v. 35, 2015. DOI: http://dx.doi.org/10.5380/dma.v35i0.38253

BRITO, G. H. M.; FERREIRA, A. A. Identificação da susceptibilidade à ocorrência de incêndios florestais para o estado de Goiás no ano de 2011. Nucleus, Ituverava, v.12, n. 1, p. 135-144, 2015. DOI: https://doi.org/10.3738/1982.2278.1406

COELHO NETTO, A. L. et al. Landslide Susceptibility in a Mountainous Geoecosystem, Tijuca Massif, Rio de Janeiro: The Role of Morphometric Subdivision of the Terrain. Geomorphology, [s.1.], v. 87, n. 3, 2007. DOI: https://doi.org/10.1016/j.geomorph.2006.03.041

COURA, P. H. F et al. Mapeamento geoecológico da susceptibilidade à ocorrência de incêndios no maciço da Pedra Branca, município do Rio de Janeiro. Anuário do Instituto de Geociências - UFRJ, Rio de Janeiro, v. 32, n. 2, 2009.

COURA, P. H. F et al. O uso de variáveis geomorfológicas no estudo da suscetibilidade à ocorrência de incêndios no estado do Rio de Janeiro. Revista de Geografia, Recife, v. especial, n. 2, 2010.

DANTAS, C. Cerrado registra mais focos de queimadas do que a Amazônia nos primeiros dias de setembro. G1 Natureza, 11 set. 2019, Disponível em:

https://g1.globo.com/natureza/noticia/2019/09/11/cerrado-registra-mais-focos-de-queimadas-doque-a-amazonia-nos-primeiros-dias-de-setembro.ghtml. Acesso em: 01 set. 2020.

DECHOUM, M. S.; ARELLANO, L. Desafios para a manutenção de serviços ecossistêmicos em parque municipal no sul do Brasil. Neotropical Biology and Conservation, São Leopoldo, v. 11, n. 3, 2016. DOI: $10.4013 /$ nbc.2016.113.05

FERNANDES, M. C. et al. Avaliação Geoecológica de Susceptibilidade à Ocorrência de Incêndios no Estado do Rio de Janeiro, Brasil. Floresta e Ambiente, Seropédica, v. 18, n. 3, 2011. DOI: http://dx.doi.org/10.4322/floram.2011.050

FREITAS, M. Onda de incêndios. O Norte, Montes Claros, 17 set. 2019. Disponível em: http://cms.hojeemdia.com.br/preview/www/2.917/2.924/1.743046. Acesso em: 31 ago. 2020.

GIGLIO, L. et al. An Enhanced Contextual Fire Detection Algorithm for MODIS. Remote Sensing of Environment, [s.1.], v. 87, n. 2-3, 2003. DOI: 10.1016/S0034-4257(03)00184-6 
GIGLIO, L. et al. The collection 6 MODIS active fire detection algorithm and fire products. Remote Sensing of Environment, [s.1.], v. 178, 2016. DOI: 10.1016/j.rse.2016.02.054

GOBBO, S. D. A. et al. Uso da terra no entorno do PARNA-Caparaó: preocupação com incêndios florestais. Floresta e Ambiente, Seropédica, v. 23, n. 3, 2016. DOI: https://doi.org/10.1590/2179-8087.110114

GOMES, B. C. V. et al. Uso do SIG na classificação de relevo no município de Toropi - RS. Revista de Geografia, Recife, v. 36, n. 2, 2019.

IEF - Instituto Estadual de Florestas. Arqueólogos pesquisam sítios no Parque Lapa Grande. 2009. Disponível em: http://www.ief.mg.gov.br/noticias/1/826. Acesso em: 30 abr. 2020.

IEF - Instituto Estadual de Florestas. Estudo técnico para ampliação dos limites do Parque Estadual da Lapa Grande, município de Montes Claros, MG. Sistema Estadual do Meio Ambiente, 2014a.

IEF - Instituto Estadual de Florestas. Estudo técnico para ampliação dos limites do Parque Estadual da Lapa Grande, município de Montes Claros, MG. Belo Horizonte: SEMAD, 2014b.

IEF - Instituto Estadual de Florestas. Plano emergencial de uso público do Parque Estadual da Lapa Grande. Sistema Estadual do Meio Ambiente, 2015.

INPE - Instituto Nacional de Pesquisas Espaciais. Portal de monitoramento de queimadas e incêndios. Disponível em: http://www.inpe.br/queimadas. Acesso em: 14 mar. 2017.

KOPROSKI, L. et al. Modelo de zoneamento de risco de incêndios para unidades de conservação brasileiras: o caso do Parque Estadual do Cerrado (PR). Floresta, Curitiba, v. 41, n. 3, 2011. DOI: http://dx.doi.org/10.5380/rf.v41i3.24049.

MADUREIRA, L. et al. Economia dos serviços de ecossistemas: um guia para conhecer e valorizar serviços de agroecossistemas em áreas protegidas de montanha. Lisboa: Quercus; 2013.

MINAS GERAIS. Decreto $\mathbf{n}^{\mathbf{0}}$ 44.204, de 10 de janeiro de 2006. Cria o Parque Estadual da Lapa Grande, no Município de Montes Claros. Disponível em:

http://www.siam.mg.gov.br/sla/download.pdf?idNorma=5310. Acesso em: 30 nov. 2019.

MIRANDA, H. S. et al. Queimadas de Cerrado: caracterização e impactos. In: AGUIAR, L. M S.; CAMARGO, A. J. A. Cerrado: ecologia e caracterização. Planaltina: EMBRAPA, 2004, p. $69-123$

MIRANDA, H. S. et al. The Fire Factor. In: OLIVEIRA, P. S.; MARQUIS, R. J. (eds.). The Cerrado of Brazil: Ecology and natural history of a neotropical savanna. New York: Columbia University Press, 2002. 69-88 p.

MOREIRA, A. A et al. Análise do Comportamento Espectral de Fitofisionomias no Parque Estadual Lapa Grande por meio de dados MODIS. Revista Brasileira de Geografia Física, Recife, v. 6, n. 6, 2013. DOI: https://doi.org/10.26848/rbgf.v6.6.p1705-1718. 
NUNES, M. T. de O. et al. Variáveis condicionantes na suscetibilidade de incêndios florestais no Parque Nacional da Itatiaia. Anuário do Instituto de Geociências - UFRJ, Rio de Janeiro, v. 38, n. 1, 2015. DOI: http://dx.doi.org/10.11137/2015_1_54_62.

ODA, M. Incêndio causa danos irreparáveis ao Parque da Lapa Grande, diz MPMG. G1 Grande Minas, 11 nov. 2015a. Disponível em: http://g1.globo.com/mg/grandeminas/noticia/2015/11/incendio-causa-danos-irreparaveis-ao-parque-da-lapa-grande-dizmpmg.html. Acesso em: 31 ago. 2020.

ODA, M. Após sete dias, incêndio no Parque da Lapa Grande é controlado. G1 Grande Minas, 12 nov. 2015b. Disponível em: http://g1.globo.com/mg/grande-minas/noticia/2015/11/apos-setedias-incendio-no-parque-da-lapa-grande-e-controlado.html. Acesso em: 31 ago. 2020.

OLIVEIRA, P. S, et al. Microcorredores ecológicos no entorno do Parque Estadual da Lapa Grande. Caminhos de geografia, Uberlândia, v. 16, n. 53, 2015.

PEIXOTO, J. Incêndio no Parque Estadual da Lapa Grande é controlado após 2 h30 de combate. G1 Grande Minas, 01 ago. 2017. Disponível em: http://g1.globo.com/mg/grandeminas/noticia/incendio-no-parque-da-lapa-grande-e-controlado-apos-2h30-de-combate.ghtml. Acesso em: 31 ago. 2020.

PEREIRA, A. A. et al. Validação de focos de calor utilizados no monitoramento orbital de queimadas por meio de imagens TM. Cerne, Lavras, v. 18, n. 2, 2012. DOI: https://doi.org/10.1590/S0104-77602012000200019.

PEREIRA, K. M. G. et al. Composição florística e fitossociológica do cerrado senso stricto no Parque Estadual da Lapa Grande, Montes Claros, MG. Enciclopédia Biosfera, Goiânia, v. 13, n. 24, 2016. DOI: 10.18677/EnciBio_2016B_026

RIBEIRO, L. et al. Zoneamento de risco de incêndios florestais para a fazenda experimental do Canguiri, Pinhais (PR). Floresta, Curitiba, v. 38, n. 3, 2008. DOI: http://dx.doi.org/10.5380/rf.v38i3.12430

RIBEIRO, L. et al. Mapeamento do rico de incêndios florestais no município de Novo Mundo, Mato Grosso, Brasil. Cerne, Lavras, v. 18, n. 1, 2012. DOI:

https://doi.org/10.1590/S0104-77602012000100014

SANTOS, A. R. et al. ARCGIS 9.3 total: aplicação para dados espaciais. Alegre: CAUFES; 2010.

SANTOS, P. R et al. Análise das queimadas no Cerrado e sua relação com o NDVI para os anos de 2000 a 2014. Revista de Geografia, Recife, v. 35, n. 2, 2018.

SANTOS JÚNIOR, V. J.; LIMA, E. P.; PRADO, R. B. Mapeamento de áreas suscetíveis à ocorrência de incêndios no Parque Estadual da Lapa Grande em Montes Claros-MG, com uso de sistema de informação geográfica. In: CONGRESSO BRASILEIRO DE REFLORESTAMENTO AMBIENTAL, 4., 2016, Rio de Janeiro. Anais [...]. Rio de Janeiro: ABAF, 2016. Disponível em: https://ainfo.cnptia.embrapa.br/digital/bitstream/item/149619/1/2016-066.pdf. Acesso: 28 ago. 2020. 
SILVA, L. C. C. et al. Mapa geoecológico de potencialidade a ocorrência de incêndios no Parque Nacional do Itatiaia/RJ. Revista Brasileira de Cartografia, Uberlândia, v. 61, n. 3, 2009.

SILVA, G. F. N. et al. Integração digital e análise espacial aplicadas ao estudo da susceptibilidade a incêndios florestais em Apiaú e Ribeiro Campos - Roraima. Revista Floresta, Curitiba, v. 38, n. 4, 2008. DOI: http://dx.doi.org/10.5380/rf.v38i4.13165.

SOARES NETO, G. B. et al. Riscos de incêndios florestais no Parque Nacional de Brasília Brasil. Territorium, Coimbra, v. 23, 2016. DOI: https://doi.org/10.14195/1647-7723_23_13.

SOUSA, G. M. et al. Cartografia geoecológica da potencialidade à ocorrência de incêndios: uma proposta metodológica. Revista Brasileira de Cartografia, Uberlândia, v. 62, 2010.

SOUZA, C. R. G. Suscetibilidade morfométrica de bacias de drenagem ao desenvolvimento de inundações em áreas costeiras. Revista Brasileira de Geomorfologia, Brasília, v. 6, n. 1, 2005. DOI: http://dx.doi.org/10.20502/rbg.v6i1.38

STEVENS, N. et al. Savanna woody encroachment is widespread across three continents. Glob. Chang. Biol., [s.l.], v. 23, 2016. DOI: https://doi.org/10.1111/gcb.13409

TORRES, F. T. P. et al. Mapeamento da suscetibilidade a ocorrência de incêndios em vegetação na área urbana de Ubá-MG. Revista Árvore, Viçosa, v. 38, n. 5, 2014. DOI: https://doi.org/10.1590/S0100-67622014000500005

TORRES, F. T. P. Mapeamento do Risco de Incêndios Florestais Utilizando Técnicas de Geoprocessamento. Floresta e Ambiente, Seropédica, v. 24, 2017. DOI: http://dx.doi.org/10.1590/2179-8087.025615

TORRES, F. T. P. et al. Influência do relevo nos incêndios em vegetação em Juiz de Fora (MG). GEOgraphia, Niterói, v. 8, n. 36, 2016. DOI:10.22409/GEOgraphia2016.1836.a13748

TORRES, F. T. P. Relações entre fatores climáticos e ocorrências de incêndios florestais na cidade de Juiz de Fora (MG). Caminhos da Geografia, Uberlândia, v. 7, n. 18, p. 162-171, 2006. DOI: https://doi.org/10.1590/S0102-77862009000400001

VALERIANO, M. M. Topodata: guia para utilização de dados geomorfológicos locais. São José dos Campos: INPE, 2008.

VIEGAS, D. X. Cercados pelo fogo. Coimbra: Minerva, 2004. 283p.

WHITE, B. L. A.; RIBEIRO, A. S. Análise da precipitação e sua influência na ocorrência de incêndios florestais no Parque Nacional Serra de Itabaiana, Sergipe, Brasil. Ambi-Agua, Taubaté, n. 6, v. 1, 2011. DOI: doi:10.4136/ambi-agua.180.

WHITE, B. L. A, WHITE, L. A. S. Queimadas controladas e incêndios florestais no Estado de Sergipe, Brasil, entre 1999 e 2015. Floresta, Curitiba, v. 46, n. 4, 2016.

WHITE, L. A. S. et al. Modelagem espacial do risco de incêndio florestal para o Município de Inhambupe, BA. Pesquisa Florestal Brasileira, Colombo, v. 36, n. 85, 2016. DOI: https://doi.org/10.4336/2016.pfb.36.85.850 
WWF-Brasil. Em 2019, área queimada na Amazônia, no Cerrado e no Pantana soma 113.743km², 30 set. 2019. Disponível em: https://www.wwf.org.br/?73242/placar-dasqueimadas-soma-113743-km2. Acesso em: 01 set. 2020.

WWF-Brasil. Implementação da Avaliação Rápida e Priorização da Gestão de Unidades de Conservação (RAPPAM) em Unidades de Conservação Estaduais de Minas Gerais. Brasília, 2016. 